\title{
ATTENUATION OF SEISMIC WAVES IN THE EARTH'S MANTLE
}

\author{
By B. Gutenberg
}

\begin{abstract}
Contrasting with conclusions from laboratory experiments that the absorption coefficient $k$ for amplitudes of elastic waves is proportional to $1 / T$, or, from theoretical considerations, that it should be proportional to $1 / T$ or to $1 / T^{2}$, observations of body waves through the mantle of the earth show little if any decrease in absorption with increasing period $T$. In teleseismic records $\mathbf{S}$ rarely shows periods of less than 4 seconds, while in $\mathrm{P}$ periods of 1 second are observed to the greatest distances. The value $k=0.06$ per $1,000 \mathrm{~km}$., found previously for $\mathrm{P}, \mathrm{P}^{\prime} \mathrm{P}^{\prime}$ and $\mathrm{P}^{\prime} \mathrm{P}^{\prime} \mathrm{P}^{\prime}$ through the mantle and the core, is confirmed for $\mathrm{P}$ and $\mathrm{PP}$ and is found also for $\mathrm{S}$ in the mantle.
\end{abstract}

IN THEORETICAL investigations of amplitudes of waves propagated through a homogeneous body it is usually assumed that the effect of attenuation can be represented by a factor $e^{-k D}$, where $k$ is called the coefficient of absorption and $D$ is the distance along the wave path. If $k$ varies in the body, $k D$ is to be replaced by a corresponding integral. For most seismic waves through the earth's mantle which do not reach the boundary of the core, especially for $\mathrm{P}, \mathrm{PP}$, and $\mathrm{S}$, the distance $D$ between source and point of observation may be replaced within the limits of other errors by the distance $\Delta$ measured along the surface of the earth. At the distance $\Delta=1 / k$ the amplitude has decreased to $1 / e$ by attenuation, at $\Delta=2.3 / k$ it has decreased to 0.1 , and at $\Delta=4.6 / k$ to 0.01 .

Various assumptions have been made to introduce attenuation effects into the equations for purely elastic waves. Frequently, a term has been added proportional to the particle velocity. In describing "firmo-elastic" processes, Sezawa (1927) has assumed that two proportionality factors, $\mu^{\prime}$ and $\lambda^{\prime}$, have to be used which correspond to Lamés constants $\mu$ and $\lambda$ in purely elastic processes. He concluded that in a medium having these properties all waves become flatter and longer during their propagation. On Stokes's assumption that the effect of firmo-elasticity on pure change in volume is negligible compared with its effect on shear, Sezawa's results indicate (Gutenberg, 1951, p. 385) that for many wave forms the period $T$ (double time between two successive crossings of the rest line in opposite directions) of wavelets is roughly given by

$$
T^{2}=T_{0}^{2}+5 \eta D / \rho V^{3}
$$

where $T_{0}$ is the period at the source, $T$ the period at a distance $D, \rho=$ density, $V=$ wave velocity, $\eta=$ coefficient of internal friction $(\eta=\tau \mu$, where $\tau=$ time of retardation in which the strain decreases to $1 / e, \mu=$ rigidity). If we write $\eta$ for $\mu^{\prime}$, Stokes's condition (Gutenberg and Schlechtweg, 1930) gives

$$
\lambda^{\prime}=\frac{2}{3} \eta \quad \lambda^{\prime}+2 \mu^{\prime}=\frac{4}{3} \eta
$$

Manuscript received for publication January 6, 1958. 
Arakawa (1931) and Sezawa and Kanai (1938) calculated $k$ assuming that $\lambda^{\prime}$ and $\mu^{\prime}$ do not depend on $T$. If we introduce $\eta$ from (2) in their equations, for plane longitudinal waves (velocity $V$ ) excluding the neighborhood of the source,

$$
k=\frac{2 \pi^{2}\left(\lambda^{\prime}+2 \mu^{\prime}\right)}{\rho T^{2} V^{3}}=\frac{8 \pi^{2} \eta}{3 \rho T^{2} V^{3}}
$$

and for plane transverse waves (velocity $v$ )

$$
k=\frac{2 \pi^{2} \mu^{\prime}}{\rho T^{2} v^{3}}=\frac{2 \pi^{2} \eta}{\rho T^{2} v^{3}}
$$

Assuming that $T_{S} / T_{P}=2$ and $V^{2}: v^{2}=3, k$ is about equal for the two wave types. Numerical results based on Sezawa's theory for Rayleigh waves have been published by Caloi (1950). A more general theory was given by Hardtwig (1952), who also concluded that the waves should become longer as they are propagated. In practically all theories for propagation of waves in absorbing solids it is found that the wave velocities do not differ noticeably from those calculated for purely elastic waves.

Ricker (1943, 1953) has based his "wavelet theory" on assumptions similar to those of Sezawa; he found that wavelets should get longer during their propagation and that for relatively long, plane longitudinal waves, $k$ is given by equation (3).

Förtsch (1956) has pointed out that on the basis of laboratory experiments the absorption coefficient in relation to the group wave length is nearly independent of frequency and the same for all wave types. He found that good agreement between theory and observations can be achieved if, in fundamental equations, to the expressions for purely elastic forces, terms for frictional forces are added which he assumes to be proportional to the absolute value of all acting forces ("Coulomb-friction"). Knopoff (1956) introduced a term describing sinusoidal motion into a differential equation of motion for a medium possessing solid friction. On his assumptions the damping coefficient of sinusoidal waves is given by

$$
k=\pi / Q T V
$$

Equation (5) also holds for a pulse, if $Q \gg 1$.

Most laboratory experiments indicate that, as in equation (5), $k$ is approximately proportional to $T^{-1}$ : Kimball and Lovell (1927), Wegel and Walther (1935), Birch and Bancroft (1938), Born (1941), Collins and Lee (1956), Lomnitz (1957), Press and Healy (1957). If equation (5) holds, the logarithmic decrement $\delta$ of vibrations in a given material and the dimensionless constant $Q=\pi / \delta$ do not depend on the period, and

$$
Q=\frac{\pi}{\delta}=\frac{\pi}{k T V}=\text { constant }
$$

Knopoff (1956) found that in materials with $Q \gg 1$, the width $T$ of a pulse is given by

$$
T=D /(V Q)
$$


and thus should increase proportional to the distance $D$. On the basis of a theory by Newlands (1954), Knopoff found for $k$ equations similar to (3) and (4). However, if $Q$ is constant, $\mu^{\prime}, \lambda^{\prime}, \eta$, and $\tau$ depend on $T$. On Sezawa's assumptions, $\tau$ is found to be of the order of 0.001 sec. (Gutenberg, 1951, p. 385) and is assumed to be independent of $T$. Experiments using vibrations with periods much smaller than $\tau$ do not show the markedly smaller amplitudes to be expected, if Sezawa's assumptions are correct. On the other hand, if $k$ is proportional to $T^{-1}$ and if $Q \gg 1$, roughly

$$
\tau=\frac{T}{2 \pi Q}
$$

which is always a small fraction of $T$.

\section{TABLE 1}

Absorption Coeffictent $k$ (per 1,000 km.) for Amplitudes, and Conresponding Order of MAGNitUde OF $Q ;(a)$ FOR SURFACE WAVES, $(b)$ FOR BODY WAVES.

\begin{tabular}{|c|c|c|c|c|}
\hline Author & Wave type & Period (sec.) & $k$ & $Q$ \\
\hline & (a) & & & \\
\hline Gutenberg (1924) ......... & Love & $100 \pm$ & 0.1 & 70 \\
\hline Gutenberg $(1945 a) \ldots \ldots$ & Rayleigh & 20 & 0.2 & 200 \\
\hline Ewing and Press $(1954) \ldots \ldots \ldots \ldots \ldots$ & Rayleigh & 140 & 0.036 & 150 \\
\hline \multirow[t]{2}{*}{ Ewing and Press $(1954) \ldots \ldots \ldots \ldots \ldots \ldots$} & Rayleigh & 215 & 0.022 & 150 \\
\hline & (b) & & & \\
\hline Gutenberg $(1945 b$, p. 58$) \ldots$ & $\mathrm{P}, \mathrm{PKP}$ & $4 \pm$ & 0.06 & 1,300 \\
\hline Gutenberg (present paper)......... & $\mathrm{P}, \mathrm{PP}$ & 2 & 0.06 & 2,500 \\
\hline Gutenberg (present paper).......... & $\mathrm{P}, \mathrm{PP}$ & 12 & 0.06 & 400 \\
\hline Gutenberg (present paper).............. & $\mathrm{S}$ & 12 & 0.06 & 700 \\
\hline Gutenberg (present paper) ............. & $\mathrm{S}$ & 24 & 0.06 & 400 \\
\hline Press $(1956) \ldots \ldots \ldots \ldots \ldots \ldots$ & $\mathbf{S}$ & 11 & $(0.09)$ & $\leqq 500$ \\
\hline
\end{tabular}

Physical theories to account for equation (6) have been suggested by Förtsch (1956) and by Knopoff and MacDonald (1957). Only relatively simple assumptions lead to equations which can be used for numerical calculations. The selection of the most appropriate theory among the many possible must be based on the observations for a given problem.

In experiments, frequently with vibrating rods, frequencies are used which are appreciably higher than those occurring in earthquake waves. Some theories (e.g., Ricker, 1943) indicate that waves with relatively low and high frequencies may behave differently. However, values of $Q$ found from laboratory experiments (Birch, 1942 ), especially $Q=150 \pm 50$ for granite in the frequency range 140 to 1600 cycles/sec. (Birch and Bancroft, 1938), are of the same order of magnitude as those found for earthquake surface waves with periods of 20 to more than 200 seconds (table 1,a). This may indicate that at least in the earth's crust $k$ is approximately proportional to $T^{-1}$. On the other hand, Kárnik (1956) combined data for Rayleigh waves with periods of between $0.001(k=200$ per $\mathrm{km}$.) and $200 \mathrm{sec} .(k=0.00002$ per $\mathrm{km}$.) and found that all data can be represented fairly well by

$$
k=0.017 T^{-1.42}
$$


A few selected data for body waves are given in table 1, $b$. Gutenberg (1945b) has found $k=0.12 \pm 0.02$ per $1,000 \mathrm{~km}$. for the absorption of the energy $(k=0.06$ for amplitudes) in $\mathrm{P}, \mathrm{P}^{\prime} \mathrm{P}^{\prime}$, and $\mathrm{P}^{\prime} \mathrm{P}^{\prime} \mathrm{P}^{\prime}$ with periods of 2 to 6 seconds. The greatest distances $D$ are about $40,000 \mathrm{~km}$. for $\mathrm{P}^{\prime} \mathrm{P}^{\prime} \mathrm{P}^{\prime}$. There are no noticeable differences in $k$ or $Q$ between longitudinal waves through the mantle and those through the core.

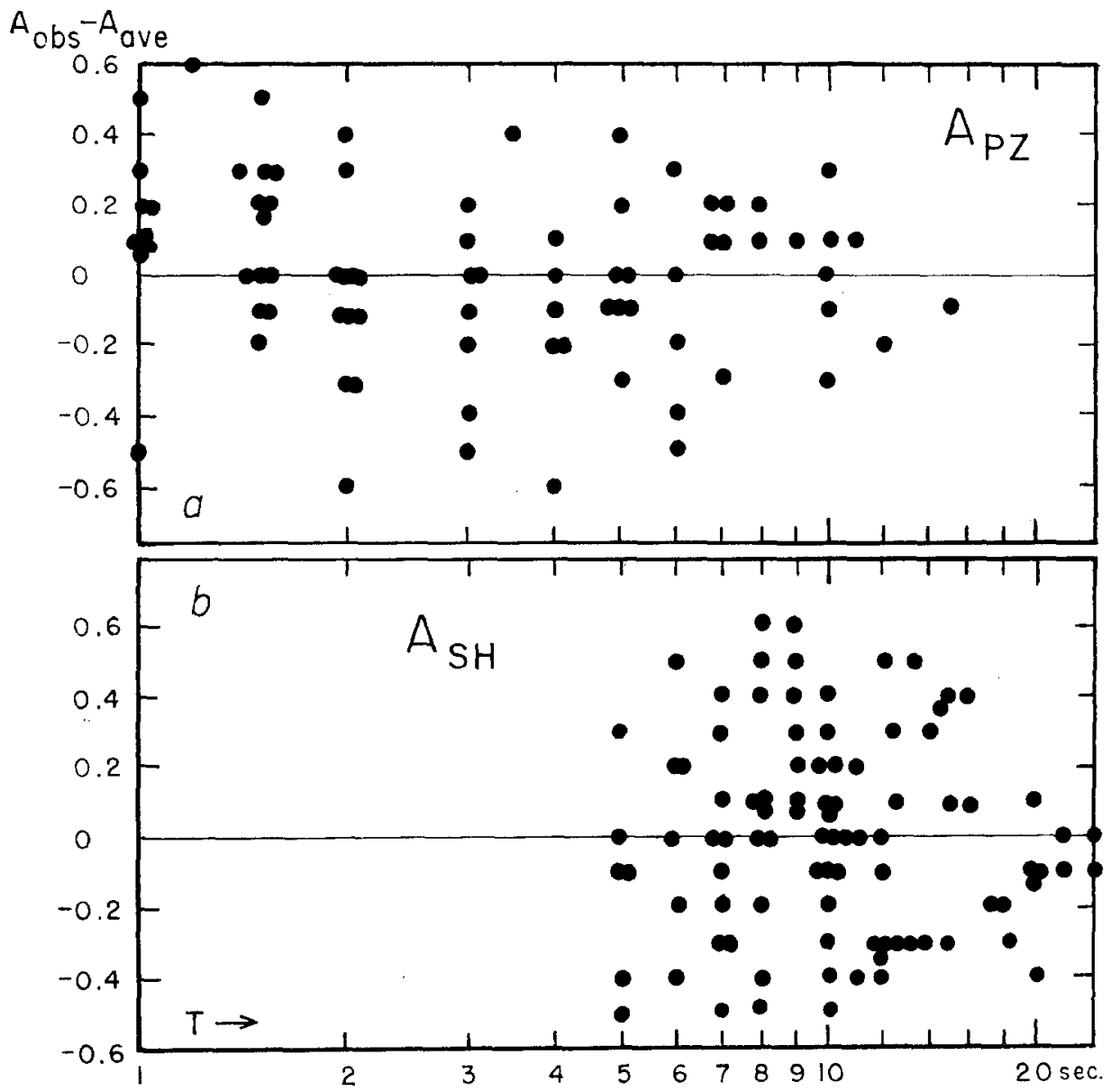

Fig. 1. Residuals of $A=m-\log (a / T)$ as function of $T$. Observed values are based on reported ground amplitudes $a$ in microns and periods $T$ in seconds for earthquakes of unified magnitude $m$ (average of all stations for a given shock); average values are taken from Gutenberg and Richter $(1956$, p. 8). Top: vertical components of P; bottom: horizontal components of $\mathrm{S}$.

The data for $\mathrm{S}$ by Press (1956) in table 1, $b$ are based on amplitudes of transverse waves reflected at the earth's core. Table $1, b$ indicates that for longitudinal waves with periods of less than 10 seconds in the mantle or in the core and for transverse waves with periods of less than 20 seconds in the mantle, $Q$ is appreciably greater than for surface waves with periods of 20 seconds or more.

To study the effect of the period $T$ on the attenuation of the amplitudes $a$ of $\mathrm{P}$, $\mathrm{PP}$, and $\mathrm{S}$ waves in the earth's mantle, residuals of $A=m-\log (a / T)$ of shocks of magnitude $m$, recorded at distances $\theta$ of $30^{\circ}$ to $105^{\circ}$ for $\mathrm{P}$ and $\mathrm{S}$ and up to $165^{\circ}$ for PP have been plotted as function of $T$ in figures 1 and $2, b$. Reports of amplitudes 

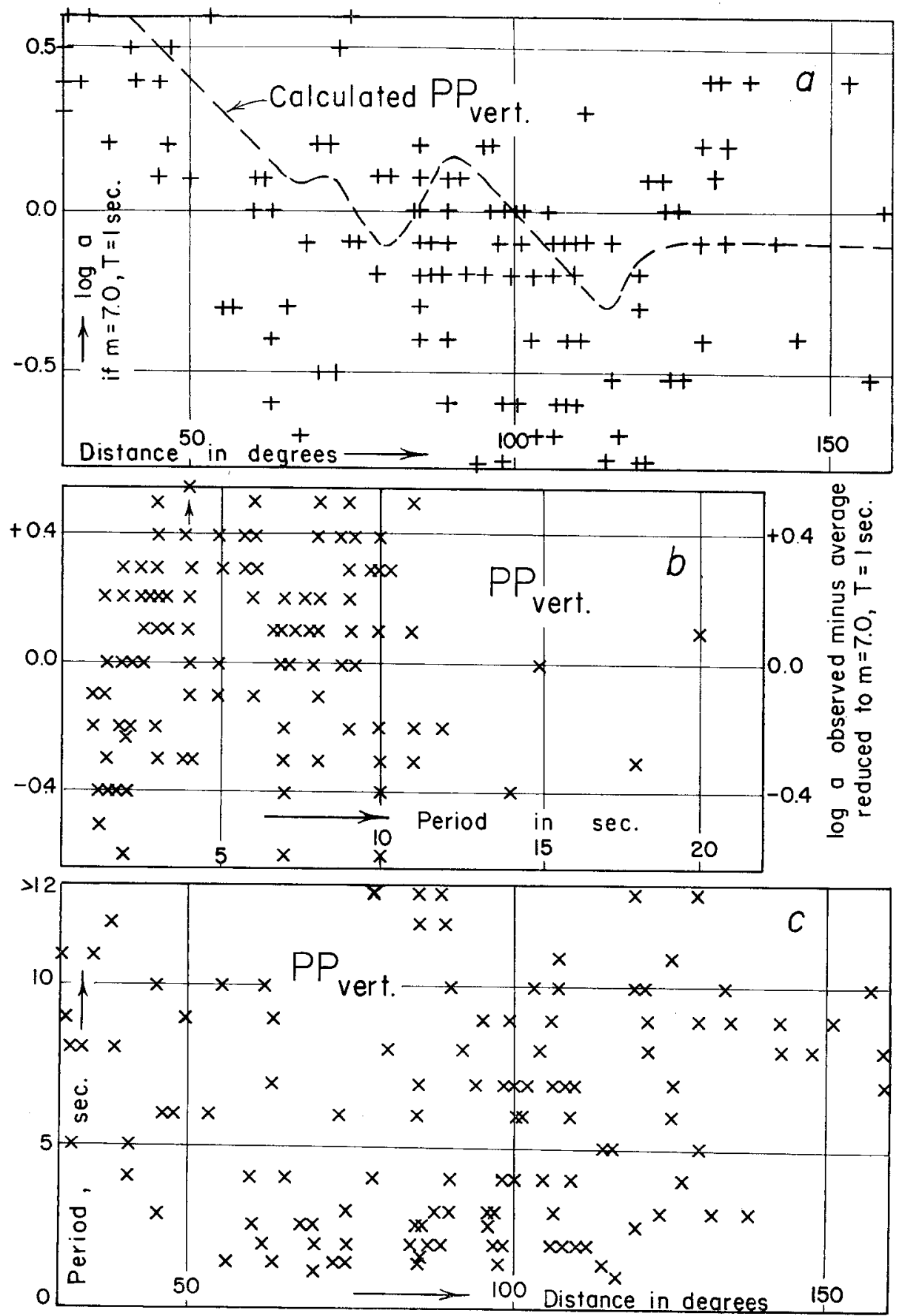

Fig. 2. Top: $\log (a / T)$ for earthquakes of magnitude $m=7.0$ as function of distance for vertical component of PP. The curve is calculated from the travel-time curve, the observations (18 stations) are reduced to $m=7$ by adding $7.0-m(m=$ magnitude of given shock). Center: residuals, observed minus average $\log (a / T)$, as function of period. Bottom: reported periods of PP as function of distance. 
and periods for more than 40 different shallow shocks between 1950 and 1954 (many with readings for several phases) have been used from Kiruna, Pasadena, Praha, and Uppsala; for 20 to 40 shocks, from La Paz, Palisades, Riverview, and Wellington; for less than 20 shocks, from Berkeley, Budapest, Christchurch, Hamburg,
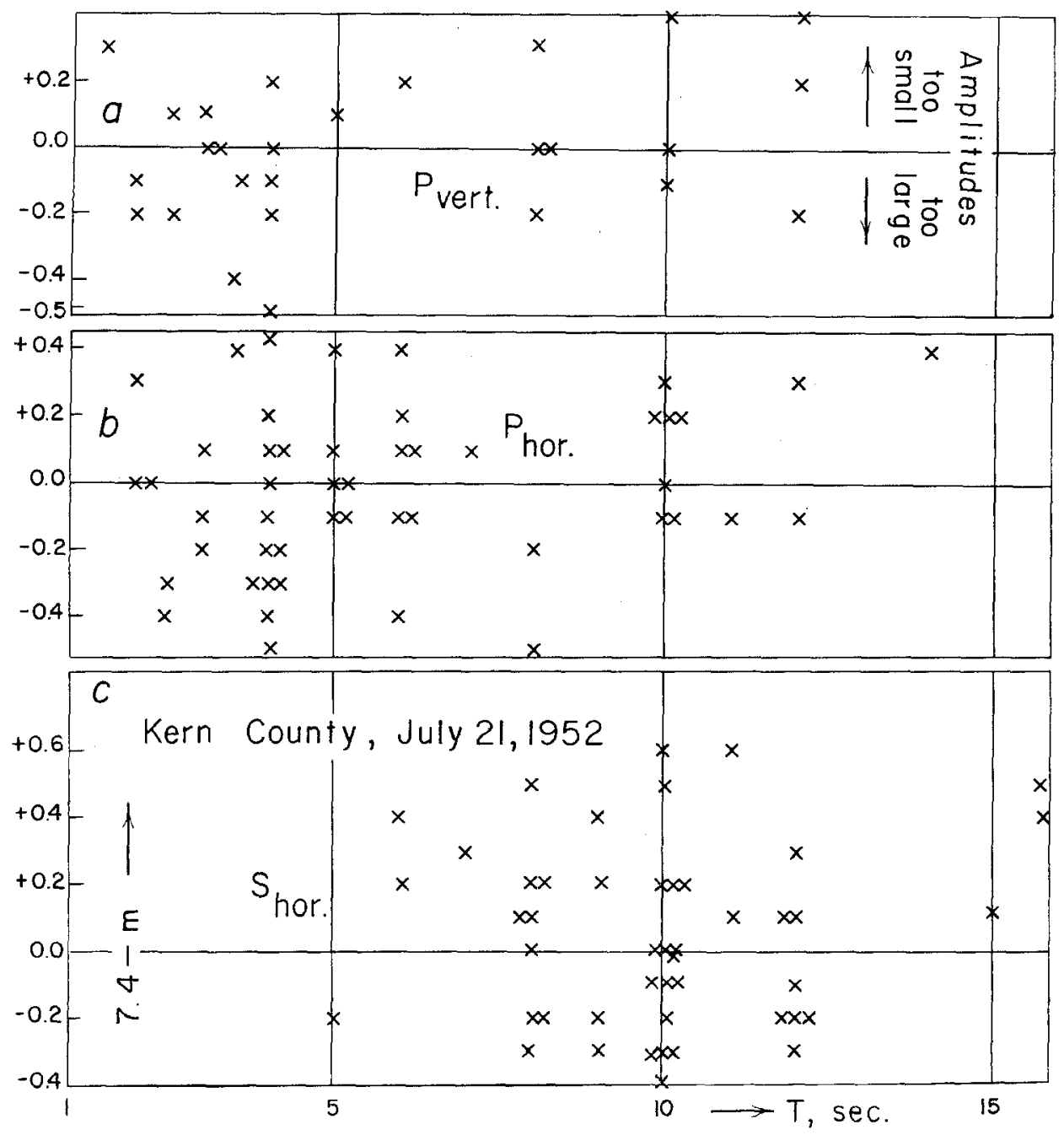

Fig. 3. Residuals as function of $T$ of individually calculated magnitudes $m$ of the main Kern County earthquake, 1952, based on $\log (a / T)$, measured on records of stations with distances over $20^{\circ}$, for vertical component of $\mathrm{P}$, its horizontal component, and the horizontal component of $\mathrm{S}$.

Honolulu, Jena, and from auxiliary stations of Praha. The magnitude $m$ is the average of all available data for $\mathrm{P}, \mathrm{PP}$, and $\mathrm{S}$, and the residuals are based on Gutenberg and Richter (1956, table 2, p. 8). Figure 3 shows residuals of $m$ for the Kern County, California, earthquake, 1952, as function of the period; they are based on individual values of $\log (a / T)$ at distances over $20^{\circ}$. No indication of a systematic difference in $\log (a / T)$ depending on $T$ has been found in these or other instances (compare table 2). Moreover, for distances over $20^{\circ}$ there is no indication of a change in prevailing periods for $\mathrm{P}, \mathrm{PP}$, or $\mathrm{S}$ as function of the distance $\theta$ (figures 4 and 5 ). 
The smallest periods observed regularly in $\mathrm{S}$ waves at distances between $20^{\circ}$ and $100^{\circ}$ are about 4 seconds, while periods in $\mathrm{P}$ waves of 1 to 3 seconds are frequently reported for all these distances. The difference between the smallest periods in $\mathrm{P}$ and in $S$ is obvious in figures 1,3 , and 6 . The prevailing ratio of about $2: 1$ between periods of $\mathrm{S}$ and $\mathrm{P}$ has been considered by Wiechert (Gutenberg, 1914, p. 195) to be a result of simultaneous generation of $P$ and $S$ waves of equal length at the source.

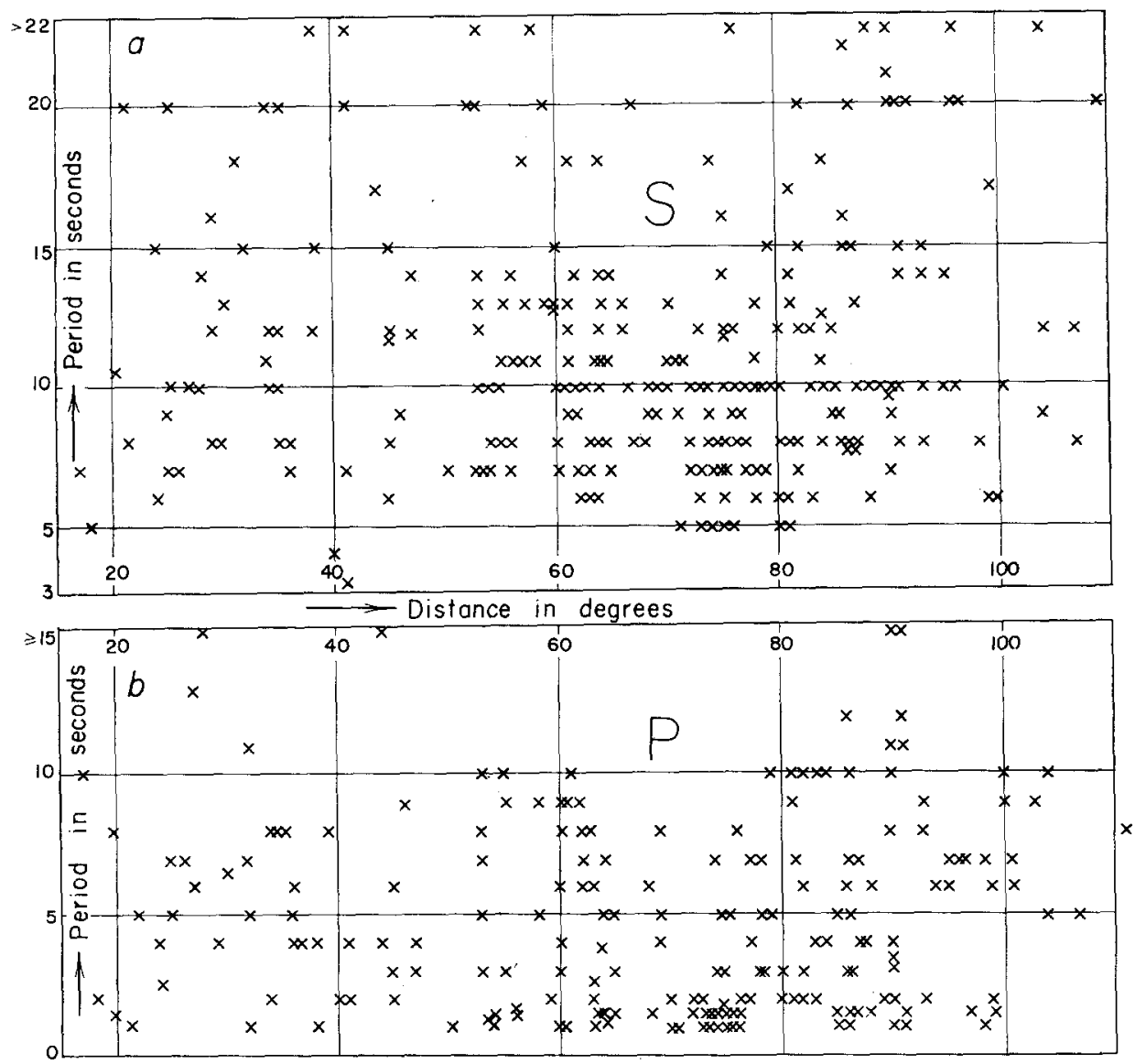

Fig. 4. Periods of waves with large amplitudes of $S$ (top) and $P$ (bottom) as function of distance for earthquakes $1950-1954$, reported by 18 stations (see text).

Gutenberg (1936) believes that frictional processes as discussed above play an important role in the lengthening of the waves at short epicentral distances. Ewing and Press (1956) consider the possibility that absorption of relatively high frequencies in $\mathrm{S}$ may involve effects of pockets of magma in the mantle.

If, in addition to processes at the source, properties of the upper portion of the mantle play a role in producing prevailing of certain periods in $\mathrm{P}$ and $\mathrm{S}$ and the lack of short periods in $\mathrm{S}$, these phenomena should be affected by the focal depth. In table 3 , data are given for the frequency of reported periods for $\mathrm{P}$ and $\mathrm{S}$ in shallow, intermediate, and deep earthquakes for the same stations and years as in figures 1 and 2 . It has to be considered that reported frequencies of periods depend on the 
characteristics of the instruments used. Moreover, most observers prefer certain periods (e.g., 10 sec. to 9). Nevertheless, table 3 indicates a shift to shorter periods with increasing focal depth for $\mathrm{P}$ as well as $\mathrm{S}$; relatively long periods become less prominent with increasing focal depth, and the spectrum contracts. More detailed study shows that the frequency curve for reported periods of $P$ has a sharp peak near $T=1$ second regardless of focal depth, while the curve for the periods of $\mathbf{S}$ has a fairly sharp peak near $T=5$ seconds in deep shocks, but more flat maxima near 8

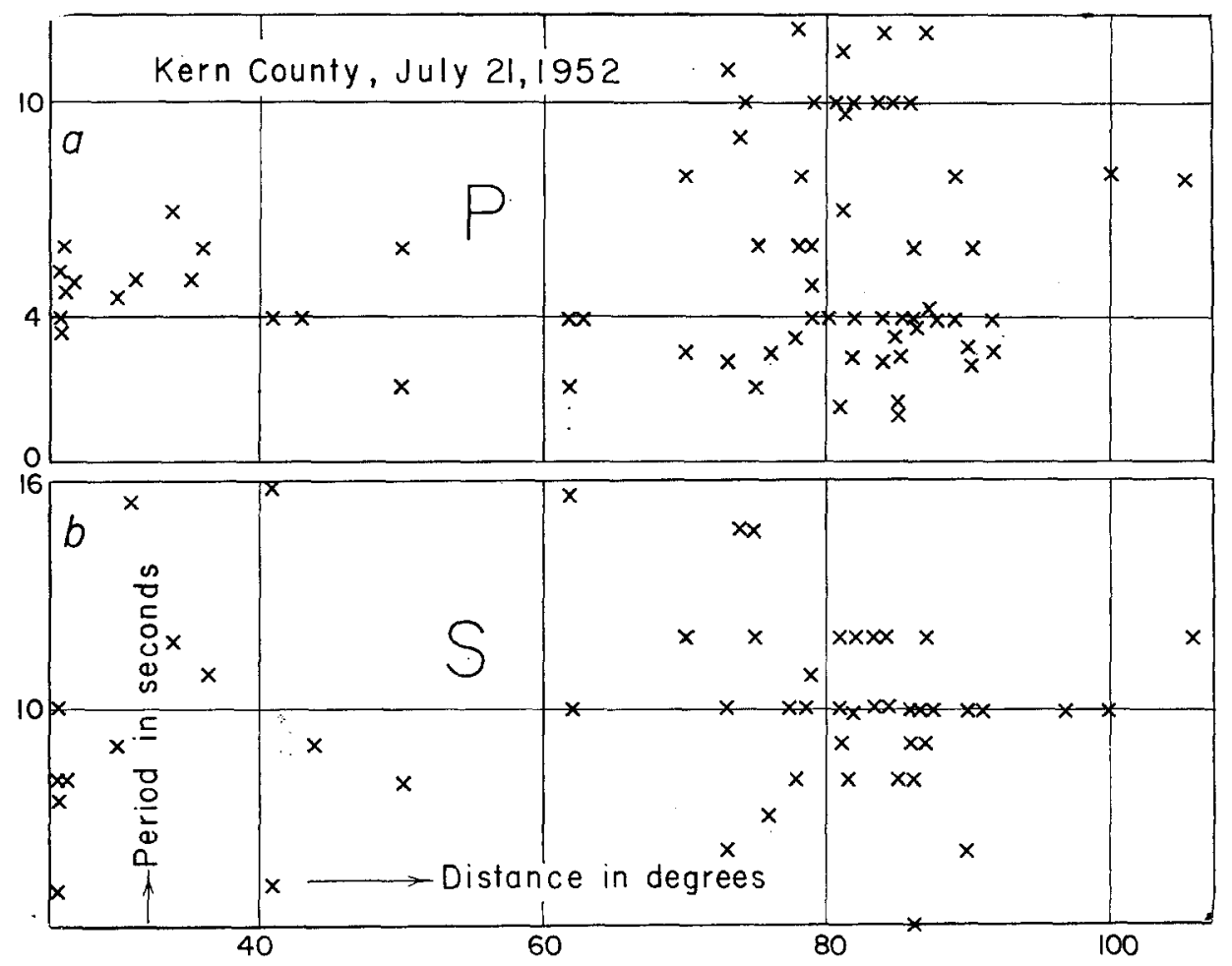

Fig. 5. Measured periods of large $P$ waves (top) and large $S$ waves (bottom) as function of distance on records of main Kern County earthquake, 1952.

and 10 seconds for intermediate and shallow shocks respectively. There is no indication that the frequency distribution of the periods changes for shocks in any of the three depth intervals as a function of epicentral distance between $20^{\circ}$ and $100^{\circ}$.

As periods of 1 second or less are observed in $S$ near the source of shallow shocks, it follows that properties of the crust and probably also of the upper portion of the mantle play an important role in increasing the periods of the most conspicuous $S$ waves (either by absorption of high frequencies, or by lengthening of the waves, or both) and in eliminating periods of less than 4 seconds. This process becomes less efficient as the focal depth increases and the waves travel less in the upper portion of the earth.

Additional data are supplied by Gutenberg (1957c) in an investigation of periods of $\mathrm{P}$ and $\mathrm{S}$ recorded simultaneously by instruments with short-period, mediumperiod, and long-period characteristics at Pasadena. All observations of $\mathrm{P}, \mathrm{PP}, \mathrm{P}^{\prime}$ 
(Gutenberg, 1957a), and S show that in each phase several distinct small ranges of periods exist for wavelets, arriving simultaneously in $\mathrm{P}, \mathrm{PP}$, and $\mathrm{S}$ (but not in $\mathrm{P}^{\prime}$ ), each of which carries relatively large energy (fig. 6). In all instances studied the two or three largest $\mathrm{P}$ wavelets in the period range of less than 10 seconds carry much more energy than any of the largest wavelets with periods of over 10 seconds. Rela-

TABLE 2

Mean Differences of Observed Values of Log $(a / T)$ Minus Their Values Corresponding to the Calculated Average Magnitude for Each Given Shock, and Standard Errors

(Material as in figs. 1 and 2. $a=$ amplitude in microns, $T=$ period in seconds, $R=$ range of distances.)

\begin{tabular}{|c|c|c|c|c|c|c|c|c|}
\hline \multicolumn{3}{|c|}{$\mathrm{P}$} & \multicolumn{3}{|c|}{$\mathrm{PP}$} & \multicolumn{3}{|c|}{$\mathrm{s}$} \\
\hline \multirow{2}{*}{$R$} & \multicolumn{2}{|c|}{$T$} & \multirow{2}{*}{$R$} & \multicolumn{2}{|c|}{$T$} & \multirow{2}{*}{$R$} & \multicolumn{2}{|c|}{$T$} \\
\hline & $1-3$ & $\geqq 8$ & & $1-4$ & $\geqq 8$ & & $4-7$ & $\geqq 14$ \\
\hline deg. & & & deg. & & & deg. & & \\
\hline $20-40$ & $0.0 \pm 0.1$ & $-0.1 \pm 0.3$ & $30-60$ & $+0.1 \pm 0.3$ & $+0.1 \pm 0.1$ & $20-40$ & $0.0 \pm 0.1$ & $+0.1 \pm 0.1$ \\
\hline $75-100$ & $-0.1 \pm 0.1$ & $-0.1 \pm 0.1$ & $120-165$ & $+0.1 \pm 0.1$ & $-0.1 \pm 0.1$ & $75-110$ & $0.0 \pm 0.1$ & $0.0 \pm 0.1$ \\
\hline
\end{tabular}

TABLE 3

Frequency (Per Cent) of Periods $T$ in Pand $S$ Waves Reported for Shallow Shocks (Focal Depth $h \leqq 60$ кM.), Intermediate $(60<h \leqq 300$ кM.), and Dekp Shocks ( $h>300$ кM.) $(n=$ number of data)

\begin{tabular}{|c|c|c|c|c|c|c|}
\hline \multirow{2}{*}{$T$} & \multicolumn{2}{|c|}{ Shallow shocks } & \multicolumn{2}{|c|}{ Intermediate shocks } & \multicolumn{2}{|c|}{ Deep shocks } \\
\hline & $\mathbf{P}$ & $\mathrm{s}$ & $P$ & $\mathrm{~s}$ & $\mathrm{P}$ & $\mathrm{S}$ \\
\hline see. & & & & & & \\
\hline $1-3 \ldots \ldots \ldots \ldots$ & 42 & 0 & 45 & 1 & 67 & 8 \\
\hline $4-6 \ldots \ldots \ldots \ldots$ & 25 & 9 & 28 & 22 & 27 & 53 \\
\hline $7-10 \ldots \ldots \ldots \ldots$ & 28 & 45 & 20 & 51 & 7 & 32 \\
\hline $11-15 \ldots \ldots \ldots$ & 6 & 30 & 7 & 19 & 0 & 8 \\
\hline$>15 \ldots \ldots \ldots \ldots$ & 0 & 16 & 0 & 7 & 0 & 0 \\
\hline$n$. & 200 & 247 & 125 & 111 & 45 & 38 \\
\hline
\end{tabular}

tively long continuation of high-frequency waves (DZ, DE in fig. 6) may result from scattering (Tatel, 1954). For $\mathrm{T}>10$ seconds the maximum energy in a single wavelet decreases with increasing period. In PP the periods of the wavelets carrying the largest energy extend to slightly greater values than in $\mathrm{P}$, but the decrease in energy for wavelets with periods of over 15 seconds is marked. Finally, in $\mathbf{S}$ the periods of wavelets carrying the largest energy extend from about 3 to 20 seconds, but the largest wavelets with periods of more than $24 \pm$ seconds rarely carry more than about one-half the energy of the shorter wavelets with the largest amplitudes.

As the prevailing periods of $\mathrm{P}$ and $\mathrm{S}$ increase at small epicentral distances (Gutenberg $1936 ; 1957 b$, p. 222), it appears that the attenuation process in the earth's crust 


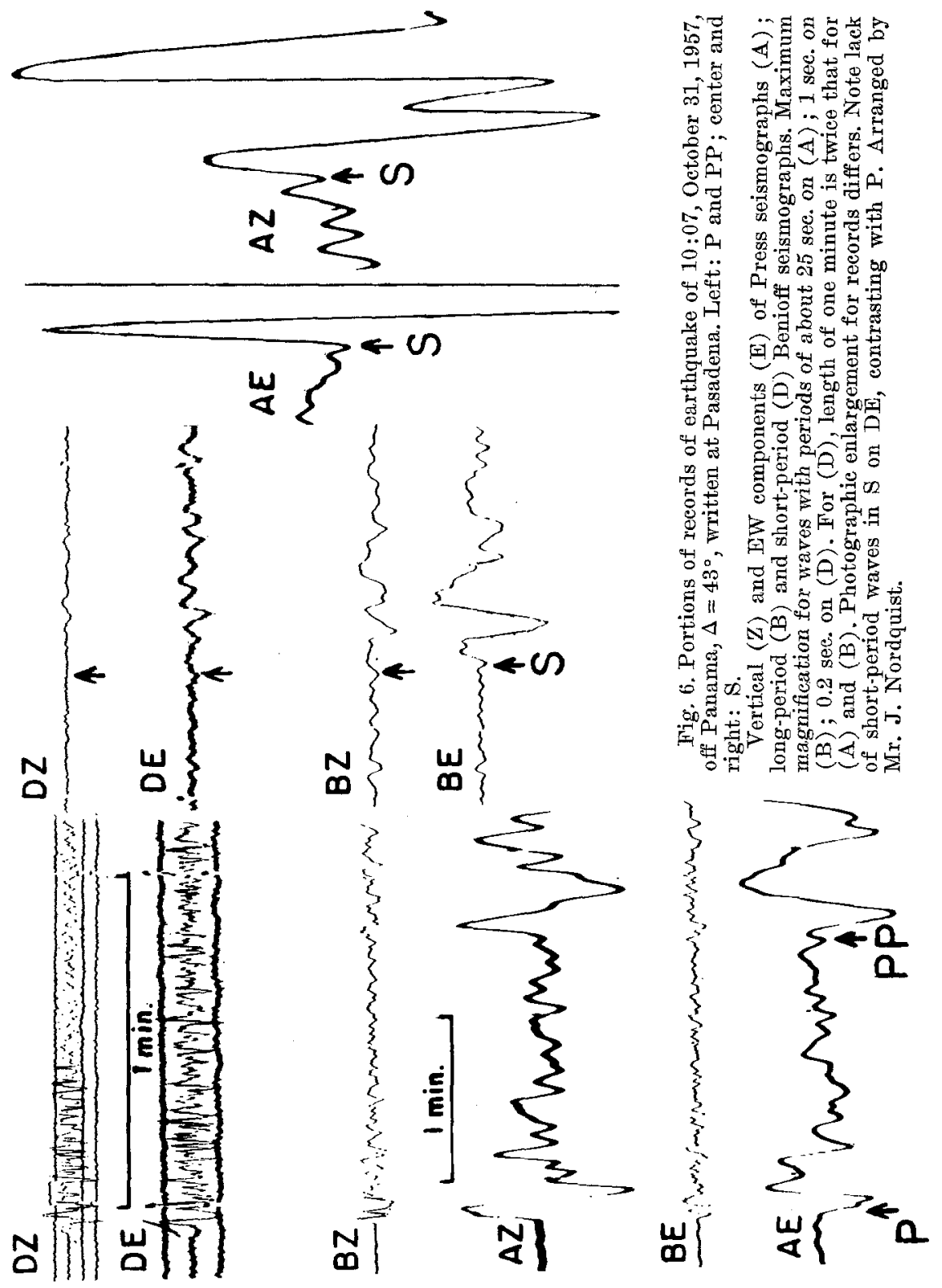


is different from that in the deeper portion of the mantle. Investigation of details for the crust and the upper part of the mantle is difficult as a consequence of the complicated wave paths and of the low-velocity channels; interpretation of observed phases at epicentral distances between roughly $2^{\circ}$ and $20^{\circ}$ is frequently doubtful.

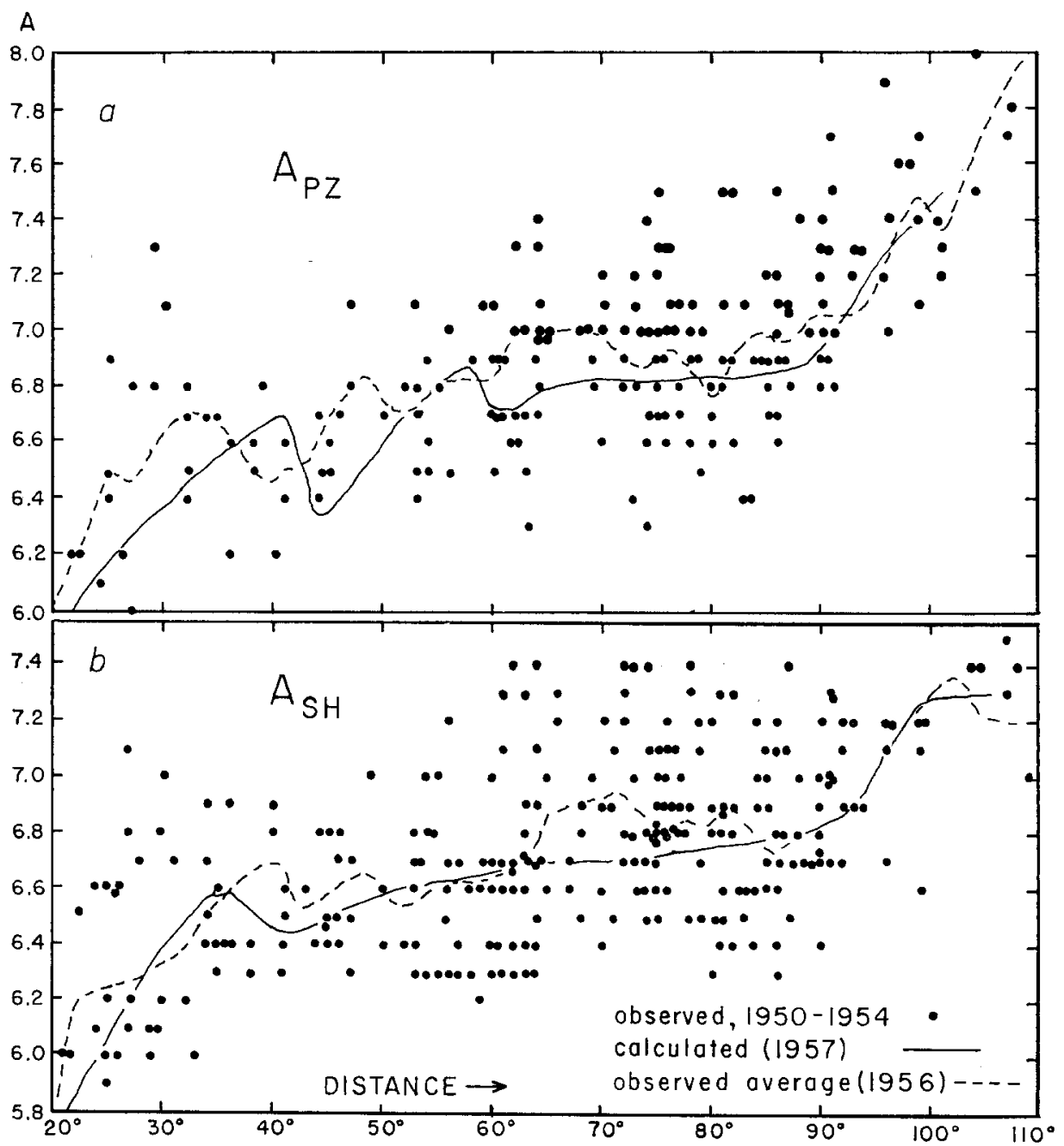

Fig. 7. Observed values of $A=m-\log (a / T)$, where $m=$ magnitude of shock, $a=$ ground amplitude in microns and $T=$ period in seconds, reported by one of 18 stations. The calculated curves are based on travel-time curves, the observed average curves on Gutenberg and Richter $(1956$, p. 8). Top: vertical component of P; bottom: horizontal component of $S$.

The attenuation of waves in the earth can also be investigated by calculating amplitudes to be expected on the basis of the observed travel times. For P, Gutenberg (1958) has used the travel times for surface foci (Gutenberg, 1953), for S those of Jeffreys-Bullen (1948), with $k=0.06$ per $1,000 \mathrm{~km}$. for the amplitudes of $\mathrm{P}$ and $\mathrm{S}$. The calculated curves for $\log (a / T)$ (figs. 2 and 7 ) agree within the limits of error with the observations and confirm that $k$ is $0.06 \pm$ for $\mathrm{P}$ and $\mathrm{S}$. 
The effect of $k$ on the amplitudes is especially large for PP at great distances. Approaching $180^{\circ}$, the contribution of the attenuation term to $\log (a / T)$ is about 0.5 , if $k=0.06$ per $1,000 \mathrm{~km}$, as assumed; table 2 shows that the effect of $T$ on $\log (a / T)$ probably does not exceed 0.1 in the same units for distances between $45^{\circ}$ and $150^{\circ}$ and periods between $2 \pm$ and $10 \pm$ seconds. These results again indicate that the effect of the period on the attenuation of body waves in the mantle is small and within the limits of errors from incorrect assumptions. There are several of these, like the neglected effect of variations with azimuth of the energy leaving the source, neglect of the (small) loss of energy at the Mohorovičic discontinuity, local variations in the reflected energy of PP. On the other hand, all reproduced results and curves are logarithms, so that an error by a factor of 1.3 in the quantity involved produces an error of only 0.1 in the result. Moreover, a variety of averages have been used, in which "errors" are minimized, unless they are systematic.

Finally, if $Q$ were constant and equal to 400 , which corresponds to $P$ waves with $T=12$ sec. (table 1 ), amplitudes of $\mathrm{P}$ waves with periods of 2 seconds would be reduced by absorption ( $k=0.36$ per $1,000 \mathrm{~km}$.) to $0.02 \pm$ at distances near $90^{\circ} \mathrm{in}-$ stead of to 0.5 for $k=0.06$, that is, to about $1 / 25$ of the observed amplitudes, and those of $\mathrm{P}^{\prime} \mathrm{P}^{\prime} \mathrm{P}^{\prime}$ with the usual periods of about 4 seconds to $0.002 \pm$ instead of to $0.1 \pm$, that is, $\mathrm{P}^{\prime} \mathrm{P}^{\prime} \mathrm{P}^{\prime}$ would not appear even on seismograms of great shocks. Much higher absorption would result if $k$ were proportional to $T^{-2}$. From all data, we may safely conclude that in the earth's mantle below about $300 \mathrm{~km}$. the absorption factor $k$ does not increase proportionally to $T^{-2}$, as indicated by equations (3) and (4). The assumption that in the mantle $k$ varies proportionally to $T^{-1}$ as in most laboratory experiments and approximately in surface waves leads to results which seem to be inconsistent with observations. A change of $k$ proportional to $T^{-\frac{1}{2}}$ could escape detection, but there is no obvious evidence for such a difference in $k$.

Summary.-Previous investigation of records of near-by earthquakes has indicated that the periods of body waves increase on paths through the upper portion of the crust. We find now that at distances beyond $20^{\circ}$ periods of a fraction of a second which exist in $\mathrm{P}$ and $\mathrm{S}$ waves near the source have disappeared, and that at distances between $25^{\circ}$ and $110^{\circ} \mathrm{S}$ waves show rarely periods of less than 4 seconds, while periods of 1 second are recorded in $\mathrm{P}$ waves to distances of $100 \pm$ degrees beyond which no direct $\mathrm{P}$ exists. There is no indication of differences in the absorption coefficient of amplitudes, $k=0.06 \pm$ per $1,000 \mathrm{~km}$., for $\mathrm{P}, \mathrm{PP}$, and $\mathrm{S}$ waves in the deeper portion of the mantle and for $\mathrm{P}^{\prime}$ waves through the mantle and core regardless of the period. The attenuation for seismic waves in the mantle cannot be represented by the same equations as for the earth's crust nor by those based on laboratory experiments. Amplitudes of seismic waves through the deep portions of the crust and the upper portion of the mantle are much more affected by complications in the paths as a consequence of the "low-velocity layers" than by absorption and, therefore, do not give useful information on the attenuation processes. 


\section{REFERENCES}

Arakawa, $\mathrm{H}$.

1931. "Dispersion and Absorption of Dilatational and Distortional Waves in Visco-elastic Solids," Geophys. Mag. Tokyo, 4: 215-223.

Birch, F.

1942. "Internal Friction in Vibrating Solids," Handbook of Physical Constants, Geolog. Soc. Am., Spec. Paper No. 36, pp. 89-92.

Birch, F., and D. Bancroft

1938. "Elasticity and Internal Friction in a Long Column of Granite," Bull. Seism. Soc. Am., 28: $243-254$.

Born, W. T.

1941. "The Attenuation Constant of Earth Materials," Geophysics, 6: 132-148.

Caloi, $\mathrm{P}$.

1950. "Comportment des ondes de Rayleigh dans un milieu firmo-elastique," Travaux Sci., Assoc. Internat. Seismol., Bur. Centr., A, 17: 89-108.

Collins, F., and C. C. Lee

1956. "Seismic Wave Attenuation Characteristics from Pulse Experiments," Geophysics, 21: 16-40.

Ewing, M., and F. Press

1954. "An Investigation of Mantle Rayleigh Waves," Bull. Seism. Soc. Am., 44: 127-147.

1956. "The Long-period Nature of S-Waves," Trans. Am. Geophys. Union, 37: 343.

Förtsch, O.

1956. "Die Ursachen der Absorption elastischer Wellen," Annali di Geofis., 9: 469-524.

Gutenberg, B.

1914. "Beobachtungen über die Perioden der Erdbebenvorläufer," Gerlands Beitr. z. Geophysik, 13: 184-196.

1924. "Dispersion und Extinktion von seismischen Oberflächenwellen und der Aufbau der obersten Erdschichten," Phys. Zeitschr., 25: 377-381.

1936. "Periods of the Ground in Southern California Earthquakes," Earthquake Investigations in California 1934-1935, U. S. Coast and Geodetic Survey, Spec. Publ. 201, pp. 163-225.

1945a. "Amplitudes of Surface Waves and Magnitudes of Shallow Earthquakes," Bull. Seism. Soc. Am., 35: 3-12.

1945b. "Amplitudes of P, PP, and S and Magnitude of Shallow Earthquakes," Bull. Seism. Soc. Am., 35: 57-69.

1951. Internal Constitution of the Earth (Dover Publ.; 439 pp.).

1953. "Travel Times of Longitudinal Waves from Surface Foci," Proc. Nat. Acad. Sci., 39: 849-853.

1957a. "The 'Boundary' of the Earth's Inner Core," Trans. Am. Geophys. Union, 38: 750-753.

1957b. "Effects of Ground on Earthquake Motion," Bull. Seism. Soc. Am., 47: 221-250.

1957c. "Spectrum of $\mathrm{P}$ and $\mathrm{S}$ in records of Distant Earthquakes," Zeitschr. f. Geophysik, 23: 316-319.

1958. "Velocity of Seismic Waves in the Earth's Mantle," Trans. Am. Geophys. Union, 39 (In press).

Gutenberg, B., and C. F. Richter

1956. "Magnitude and Energy of Earthquakes," Annali di Geofis., 9: 1-15.

Gutenberg, B., and H. Schlechtweg

1930. "Viskosität und innere Reibung fester Körper," Phys. Zeitschr., 31: 745-752.

Hardtwig, E.

1952. "Ueber die Formänderung mikroseismischer Wellen während des Ausbreitungsvorganges," Pontif. Acad. Sci., Scripta Varia, 12: 367-386.

Jeffreys, $\mathrm{H}$.

1931. "Damping in Bodily Seismic Waves," Geophys. Suppl., 2:318-323.

Jeffreys, H., and K. E. Bullen

1948. Seismological Tables (Brit. Assoc. Adv. Sci., London; 50 pp.). 
Kárnik, $V$.

1956. "Magnitudenbestimmung europäischer Nahbeben," Traveaux Inst. Geophys. Acad. Tchecoslov. Sci., No. 47; 124 pp.

Kimball, E. L., and D. E. Lovell

1927. "Internal Friction in Solids," Physical Review, 30:948-959.

Knopoff, L.

1956. "The Seismic Pulse in Materials Possessing Solid Friction, 1: Plane Waves," Bull. Seism. Soc. Am., 46: 175-183.

Knopoff, L., and G. J. F. MacDonald

1957. "The Attenuation of Small Amplitude Stress Waves in Solids," oral presentation; to be published.

Lomnitz, C.

1957. "Linear Dissipation in Solids," Jour. Applied Physics, 28; 201-205.

Newlands, $M$.

1954. "Lamb's Problem with Internal Dissipation," Jour. Acoust. Soc. Am., 26: 434-448.

Press, F.

1956. "Rigidity of the Earth's Core," Science, 124: 1204.

Press, F., and J. Healy

1957. "Absorption of Rayleigh Waves in Low Loss Media," Jour. Applied Physics, 28: 13231325.

Ricker, $\mathrm{N}$.

1943. "Further Developments in the Wavelet Theory of Seismogram Structure," Bull. Seism. Soc. Am., 33: 197-228.

1953. "The Form and Laws of Propagation of Seismic Wavelets," Geophysics, 18: 10-40.

Sezawa, K.

1927. "On the Decay of Waves in Viseo-elastic Solid Bodies," Bull. Earthq. Res. Inst. Tokyo, $3: 43-53$.

Sezawa, K., and K. Kanai

1938. "Damping of Periodic Visco-elastic Waves with Increase in Focal Distance," Bull. Earthq. Res. Inst. Tokyo, 16: 491-502.

Tatel, H. E.

1954. "Note on the Nature of a Seismogram," Jour. Geophys. Res., 59: 289-294.

Wegel, R. I., and H. Walther

1935. "Internal Dissipation in Solids for Small Cyclic Strains," Physics, 6: 141-157.

California Institute of Technology,

Pasadena, California.

(Diviston of the Geological Sciences, Contribution no. 854) 